\title{
Exploring an Interactive Value-Adding Data-Driven Model of Consumer Electronics Supply Chain Based on Least Squares Support Vector Machine
}

\author{
Xiao-le Wan, ${ }^{1,2}$ Zhen Zhang, ${ }^{3}$ Xiao-xia Rong, ${ }^{3}$ and Qing-chun Meng ${ }^{1,2}$ \\ ${ }^{1}$ School of Management, Shandong University, Jinan 250100, China \\ ${ }^{2}$ Research Center for Value Co-Creation Network, Shandong University, Jinan 250100, China \\ ${ }^{3}$ School of Mathematics, Shandong University, Jinan 250100, China \\ Correspondence should be addressed to Qing-chun Meng; meqich@sdu.edu.cn
}

Received 18 May 2016; Accepted 17 July 2016

Academic Editor: Junhu Ruan

Copyright (C) 2016 Xiao-le Wan et al. This is an open access article distributed under the Creative Commons Attribution License, which permits unrestricted use, distribution, and reproduction in any medium, provided the original work is properly cited.

\begin{abstract}
The differences in supply chains and their competitiveness depend on the differences in supply chain value creation systems. On the basis of the theory of value cocreation, this study investigates the interactive value creation of consumer electronics supply chains from the perspective of the interaction and added value created by the main value creation bodies in supply chains. Least squares support vector machine (LS-SVM) is innovatively introduced into the study on consumer electronics supply chains. A data-driven model is also established, the parameters of the method and kernel functions are optimized and selected, and an LS-SVM algorithm of consumer electronics supply chains is proposed to deal with the limited number of samples. Then, an empirical analysis of the top 10 smartphone supply chains in the Chinese market is conducted, and the LS-SVM model and other forecasting methods are compared. Results suggest that the LS-SVM model achieves a good predictive accuracy. This study also analyzes the value-adding structure of supply chains from the perspective of interaction and enriches the theory of value creation among supply chains. This study is conducive to helping consumer electronics enterprises to conduct market analyses and determine value growth points accurately.
\end{abstract}

\section{Introduction}

The continuous development of information technologies in recent years has resulted in the constant advancement of the consumer electronics industry under the social background of technological innovation. The consumer electronics industry has become the largest and fastest growing manufacturing industry in the world [1]. After 10 years of rapid development, the Chinese consumer electronics market reached the industrial scale of $\$ 4,059.01$ billion in 2014; this value equated to $54.1 \%$ of the global share [2]. China has become the largest producer and consumer of electronic products. The Chinese consumer electronics industry has maintained its output value in trillion yuan and has become one of the major hightech industries of the national economy. This industry has also played a positive role in improving the development level of social informatization and in promoting the integration of information and industrialization.

However, the extensive integration of the "Internet+" strategy and advanced information technologies, including mobile Internet, wireless sensing networks, Internet of Things, and cloud computing, has exerted unprecedented effects on consumer behavior and has raised new user requirements, thereby leading to new product types and intense market competition. In addition, high and new technologies promote the rapid emergence of new consumer electronic products. Intelligent production enables online production to keep abreast of offline production, subjects the traditional consumer electronics industry to the catfish effect, and intensifies the global competition in the consumer electronics industry. Therefore, the core competitive advantage of consumer electronics enterprises and the international 
competitiveness of the consumer electronics industry must be enhanced.

The competition among consumer electronics enterprises revolves around supply chains. From the perspective of performance, the formation and source of supply chain competitive advantage depend on the operational efficiency and effectiveness of supply chains, the essence of which is the supply chain value creation system. The differences in supply chains and their competitiveness depend on the differences in supply chain value creation systems [3].

Traditional value creation theory contends that value is independently created by enterprises, whereas customers are the consumers of value $[4,5]$. However, the theory of value cocreation fundamentally subverts the traditional value creation logic by indicating that a producer is not the sole value creator; that is, consumers can also create value $[6,7]$. Consumers can create value in production and consumption [7]. However, the theory of value cocreation constantly expands toward the outer periphery of supply chains in practice. Some main value creation bodies excluded from supply chains tend to participate in supply chain value creation in different forms and exert an unexpected effect; specifically, these value creation bodies participate in open innovation [8], government policies and regulation $[9,10]$, and guidance of industry associations [11].

From the perspective of the supply chain structure, different value creation bodies represent the contradiction between a traditional value creation idea and the theory of value cocreation either in a broad sense or in a narrow sense. The theory of value cocreation is a redeconstruction of the original supply chain value creation body, which transforms from the original single-value creator enterprise into one in which two value creators, namely, enterprises and consumers, or multiple value creators are involved. Therefore, the changes in value creators inevitably lead to different views on the value creation method. These changes also result in the differences in supply chain value creation systems.

Many scholars have considered consumers as supply chain value creators. Xiao et al. [12] considered that, under the e-commerce situation, the partner-based supply chain should be transformed into a consumer-oriented supply chain; they also suggested that consumers are the future and end of supply chain value creation. Meng et al. $[13,14]$ adopted a new prosumer model and mathematical models to conduct a series of studies and determined that the alliance of consumers and enterprises can improve supply chain value. Huang et al. [15], Cavalieri and Pezzotta [16], and Zhen [17] introduced consumers into the service-oriented manufacturing supply chain management system and turned them into "coproducers"; specifically, they provided production services and service-oriented production activities to maximize and increase customer value and enterprise value. Shen [3] noted that the overall value of a supply chain is created by the joint efforts of suppliers, manufacturers, distributors, and consumers. In addition, some off-chain value creators (such as an open innovation body) are incorporated into supply chain value creation systems, as described in some preliminary theoretical studies and practices. Niu [18] used fuzzy mathematics theory, established a factor analysis model, and determined that open innovation exerts a crucial effect on the development of cluster supply chains. Sakamoto et al. [8] contended that enterprises should use open innovation as the key factor to enhance supply chain competitiveness and add value. IBM established the first supply chain innovation center in China to integrate and transform the global supply chain capability of the country by assisting global enterprises [19]. The aforementioned studies are based on the maximization of supply chain value, and they include consumers or other relevant participants into the supply chain value cocreation system. However, these studies fail to explain the microscopic mechanism of supply chain value creators after deconstruction.

As a result of the development of advanced information technologies, the integration of intelligence and the interconnection highlights the increasingly prominent role of consumers with regard to consumer electronic products, including mobile Internet, wireless sensing networks, Internet of Things, and cloud computing. An increasing number of consumers involved in the value creation process have become the most important value creators of consumer electronics supply chains. For example, Xiaomi represents the typical value cocreation of a consumer electronics supply chain; this company took only four years to become the fifth largest mobile phone provider in the world (IDC Report, 2015). In addition, open innovation gradually narrows the interaction between an enterprise and external parties; thus, most of the innovative ideas of an enterprise come from outside forces. For example, consumer electronics supply chain brands Haier and Midea have successfully shifted to open innovation. Obviously, the traditional enterprise-oriented supply chain creation mode cannot effectively explain the value creation problems of consumer electronics supply chains. Thus, value cocreation has become a new method for creating supply chain value.

From a deep point of view, the core of value cocreation theory is that the value creator completes value cocreation behavior through heterogeneity interaction; interaction provides the value creator with a means to achieve value cocreation $[7,20]$. Technical innovation blurs the boundaries between companies and individuals and provides increasing opportunities for the interaction between enterprises and consumers and for the interaction among consumers [21]. Consumers create value through their consumption practices or through the interaction opportunities provided by enterprises [22]. Interaction is a service experience and user value creation model [23]. It also represents the capacity of enterprises and consumers to obtain useful information and achieve value effectively and constantly [24]. Therefore, interaction can be regarded as a competitive advantage of enterprises and a heterogeneous resource to improve value creation ability $[24,25]$.

The least squares support vector machine (LS-SVM), which is based on the equality constraint and the least squares loss function, is an extension of SVM [26]. LS-SVM is also used to solve pattern recognition, image classification, and nonlinear function estimation problems $[27,28]$. Langone et al. [29] applied the LS-SVM approach with spectral clustering and regression to predict the maintenance of 


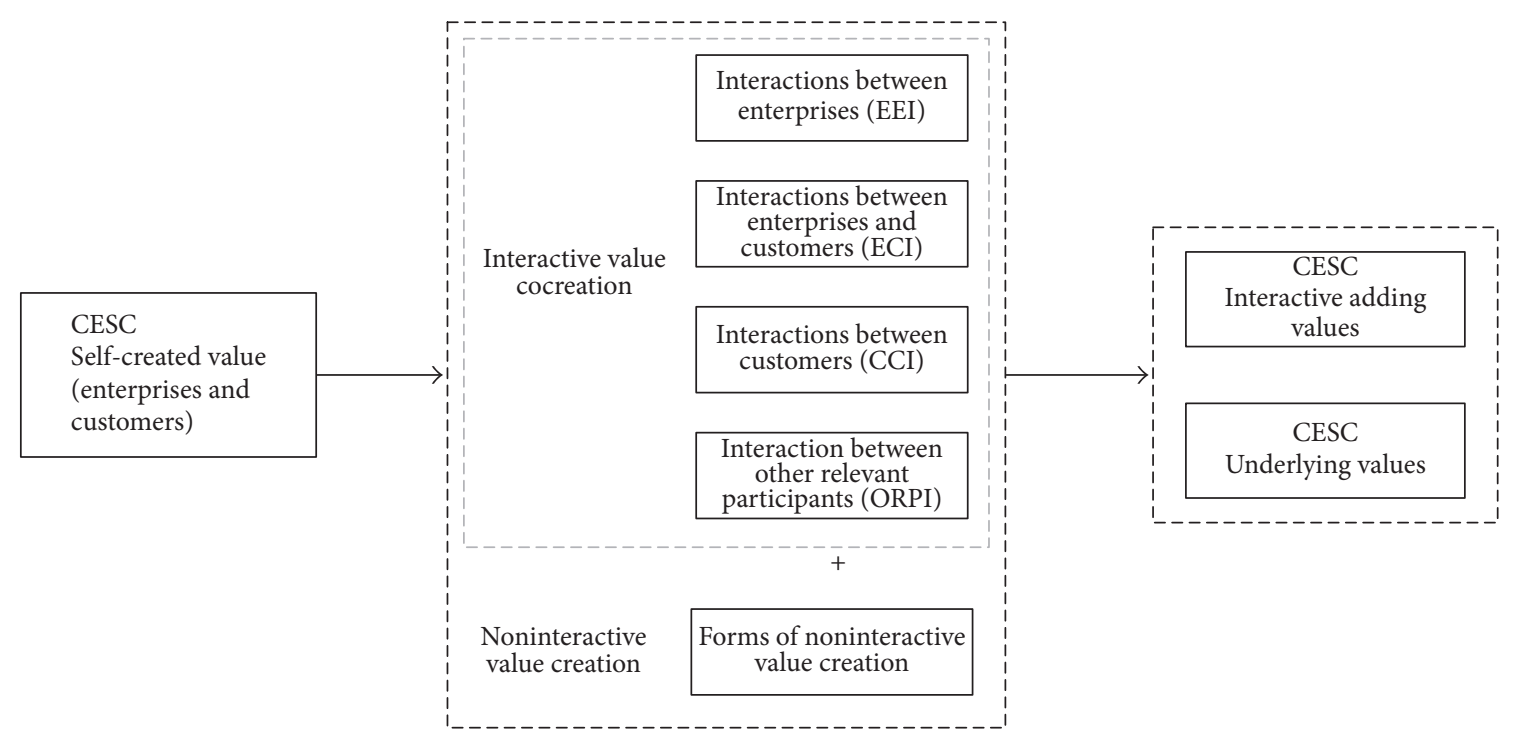

FIGURE 1: Value creation system of consumer electronics supply chains based on interaction.

industrial machines. Zhang and Shetty [30] adopted the LSSVM approach to predict the surface roughness in machined surfaces. Yuan et al. [31] built an LS-SVM model to predict short-term wind power. Yu et al. [32] used LS-SVM to predict the temperature in a Chinese solar greenhouse. The LS-SVM method achieves a good prediction performance in regression forecasting. Although the LS-SVM method has been widely used for regression prediction in many disciplines, such as engineering, chemistry, meteorology, and environmental issues, the application of LS-SVM in the prediction of supply chain value is not extensively studied. The supply chain value creation problem exhibits industryspecific features and involves complex nonlinear problems that are jointly constituted by upstream and downstream enterprises, consumers, and other related parties [33]. The problem of a limited sample size (such as consumer electronics supply chains) inevitably emerges when focusing on the value creation issues of a specific industrial supply chain. The LS-SVM method achieves good adaptability in view of these two characteristics: the LS-SVM method has remarkable nonlinear mapping capabilities in prediction [34], and the LS-SVM method usually demonstrates good generalization ability even with a small sample size [35].

In the present study, we first consider the theory of value cocreation to explore the internal value creation mechanism of consumer electronics supply chains. This study also considers consumers, open innovation bodies, and other internal and off-chain bodies included in the value creation system of consumer electronics supply chains. The value creation system of consumer electronics supply chains is established such that it meets the actual development condition and the status of the consumer electronics industry. It innovatively introduces LS-SVM into the study on consumer electronics supply chains, establishes an interactive value-adding datadriven model, and optimizes and selects the parameters and kernel functions of the method to improve its prediction accuracy. Finally, the LS-SVM model and other prediction methods are compared, and the results are combined with the empirical data.

The remaining parts of this paper are arranged as follows. Section 2 establishes the value creation system of consumer electronics supply chains. Section 3 presents an LS-SVMbased data-driven model of consumer electronics supply chains and proposes a relevant algorithm. Section 4 conducts an empirical analysis of the Chinese smartphone supply chain and offers preliminary policy recommendations. Section 5 discusses the comparative study on the four different forecasting models and common kernel functions. Section 6 presents the conclusion.

\section{Supply Chain Value Creation System Based on Interaction}

According to the perspective of value cocreation, the supply chain value (system output) process is established on the basis of the independent creation of supply chain value creators (system input). This process is jointly achieved by various value creators through heterogeneous interactions and other noninteractive value behaviors (Figure 1).

The supply chain value creation process can be divided into two organic stages. The first stage is the basic value creation process of supply chains. Porter value chain theory explains that enterprises and consumers can create their own value, use this value as an initial supply chain value, input this value into the basic process subsystem of supply chain value creation, adopt a series of noninteractive value creation behaviors, and output the basic value of the supply chain. The second stage is the interactive value-adding supply chain process. Self-created value plays a key role in interactive value creation [36]. The basic value of a supply chain is the input value of the value creation subsystem; the added value of a supply chain is output through the heterogeneous 
interactions among various value creators. These two stages occur simultaneously, and they serve as mutually initial values in the continuous and dynamic value creation process. These processes also reflect and enhance each other, and they promote harmony.

In the process of creating added value in the supply chain, interaction effectively increases value and serves as a main carrier of supply chain value-adding factors. Interaction mainly comes from the interaction among supply chain value creators. The theory of value cocreation mainly refers to the value cocreation or interaction between enterprises and consumers. However, Payne et al. [37] considered that the main parts of value cocreation activities are customer value creation, supplier value creation, and interface. Saarijärvi et al. [38] emphasized that "value," "cocreation," and "creation" mean that enterprise value or consumer value is created by different bodies through different forms of activities (B2C, $\mathrm{B} 2 \mathrm{~B}, \mathrm{C} 2 \mathrm{~B}$, or $\mathrm{C} 2 \mathrm{C}$ ). Moreover, interaction occurs between a consumer and a product (or service) provider and among all the bodies in the value network [39]. However, in practice, interaction occurs in all the cocreation behaviors of the main bodies in the supply chain. Furthermore, cocreation behaviors constitute the interactive value-adding structure of the supply chain.

The present study does not focus on the basic value creation process of supply chains and mainly explores the influence of interactive cocreation behaviors on supply chain value in the value-adding process. The report [40] performs a literature review and qualitative research and starts from the interaction and cocreation among enterprises, consumers, other participants, and main bodies; it also adopts the DelphiAHP evaluation method to construct an interactive valueadding index system of supply chains (Table 1 ). This system includes 4 primary indicators, 14 secondary indicators, and 44 tertiary indicators. The index system characterizes the features of consumer electronics supply chains. Any change in an indicator causes a change in the output value of the interactive value-adding system.

\section{Data-Driven Model of Consumer Electronics Supply Chains Based on LS-SVM}

3.1. Data Collection. According to the interactive value-adding index system of consumer electronics supply chains in Table 1, the senior supply chain experts of the consumer electronics industry are invited to participate. Moreover, a five-point Likert scale is adopted, the $v$ th $v(v=1,2,3)$ indicator of $N$ supply chains is quantified and scored, and the input vector of the $l$ th interactive value-adding electronics supply chain system $x_{l}^{v}$ is obtained. The actual value of the $l$ th interactive value-adding electronics supply chain system is recorded as $y_{l}$. Thus, the original data set of the datadriven model of consumer electronics supply chain $\left\{x_{l}^{v}, y_{l}\right\}_{l=1}^{N}$ is obtained.

3.2. Model Construction. The training set $\left\{x_{k}^{v}, y_{k}\right\}, k=$ $1,2, \ldots, n, 1<n \leq N$, is selected; here, $x_{k}^{v} \in R^{d^{v}}$, where $x_{k}^{v}$ refers to the variable of the $v$ th indicator that affects the value of consumer electronics products, $v=1,2,3$, and $y_{k}$ refers to the value of the consumer electronics supply chain. The $v$ th indicator's driving model of the consumer electronics supply chain based on LS-SVM is assumed as follows:

$$
y_{\mathrm{CESC}}^{v}\left(x^{v}\right)=\left(G^{v}\right)^{T} \varphi\left(x^{v}\right)+b^{v}
$$

where $y_{\text {CESC }}^{v}$ is the model predictive value of the $v$ th indicator, $\left(G^{v}\right)^{T}$ is the weight vector, $\varphi\left(x^{\nu}\right)$ denotes nonlinear mapping from the input space to the high-dimensional feature space, and $b^{v}$ is a partial vector [41].

According to the LS-SVM method, the error loss function $e_{v_{k}}^{2}$ and error penalty factor $\gamma$ are introduced. The above problem (1) can be transformed into Model (2) as follows:

$$
\begin{aligned}
& \min J\left(G^{v}, e^{v}\right)=\frac{1}{2}\left(G^{v}\right)^{T} G^{v}+\frac{\gamma^{v}}{2} \sum_{k=1}^{n} e_{v_{k}}^{2} \\
& \text { s.t. } \quad y_{k}=\left(G^{v}\right)^{T} \varphi\left(x_{k}^{v}\right)+b^{v}+e_{v_{k}}, \\
& \quad k=1,2, \ldots, n .
\end{aligned}
$$

The Lagrange function is defined as

$$
\begin{aligned}
& L\left(G^{v}, \gamma^{v}, e^{v}, a^{v}, b^{v}\right) \\
& =\frac{1}{2}\left(G^{v}\right)^{T} G^{v} \\
& \quad+\sum_{k=1}^{n}\left(\frac{\gamma^{v}}{2} e_{v_{k}}^{2}-a_{k}^{v}\left(\left(G^{v}\right)^{T} \varphi\left(x_{k}^{v}\right)+b^{v}+e_{v_{k}}-y_{k}\right)\right) .
\end{aligned}
$$

According to the KKT conditions of MP, the solution of problem (2) is equivalent to solving the following equations:

$$
\begin{gathered}
G^{v}=\sum_{k=1}^{n} a_{k}^{v} \varphi\left(x_{k}^{v}\right), \\
\sum_{k=1}^{n} a_{k}^{v}=0, \\
a_{k}^{v}=\gamma^{v} e_{v_{k}}, k=1, \ldots, n, \\
G^{v} \cdot \varphi\left(x_{k}^{v}\right)+b^{v}+e_{v_{k}}-y_{k}=0, \quad k=1, \ldots, n .
\end{gathered}
$$

The kernel function is defined as $K\left(x_{i}^{v}, x_{j}^{v}\right)=\varphi\left(x_{i}^{v}\right) \cdot \varphi\left(x_{j}^{v}\right)$, and $G^{v}$ and $e_{v}$ are eliminated. Problem (4) can be converted into the following equation:

$$
\left(\begin{array}{cc}
0 & \left(I_{n}^{v}\right)^{T} \\
1 & K\left(x_{i}^{v}, x_{j}^{v}\right)+\frac{1}{\gamma^{v}}
\end{array}\right)\left\{\begin{array}{l}
b^{v} \\
a^{v}
\end{array}\right\}=\left\{\begin{array}{c}
0 \\
y_{\text {CESC }}^{v}
\end{array}\right\} .
$$

The solutions $a^{v}$ and $b^{v}$ are calculated. Thus, the datadriven model based on LS-SVM is as follows:

$$
y_{\mathrm{CESC}}^{v}\left(x^{v}\right)=\sum_{k=1}^{n} a_{k}^{v} K\left(x^{v}, x_{k}^{v}\right)+b^{v} .
$$




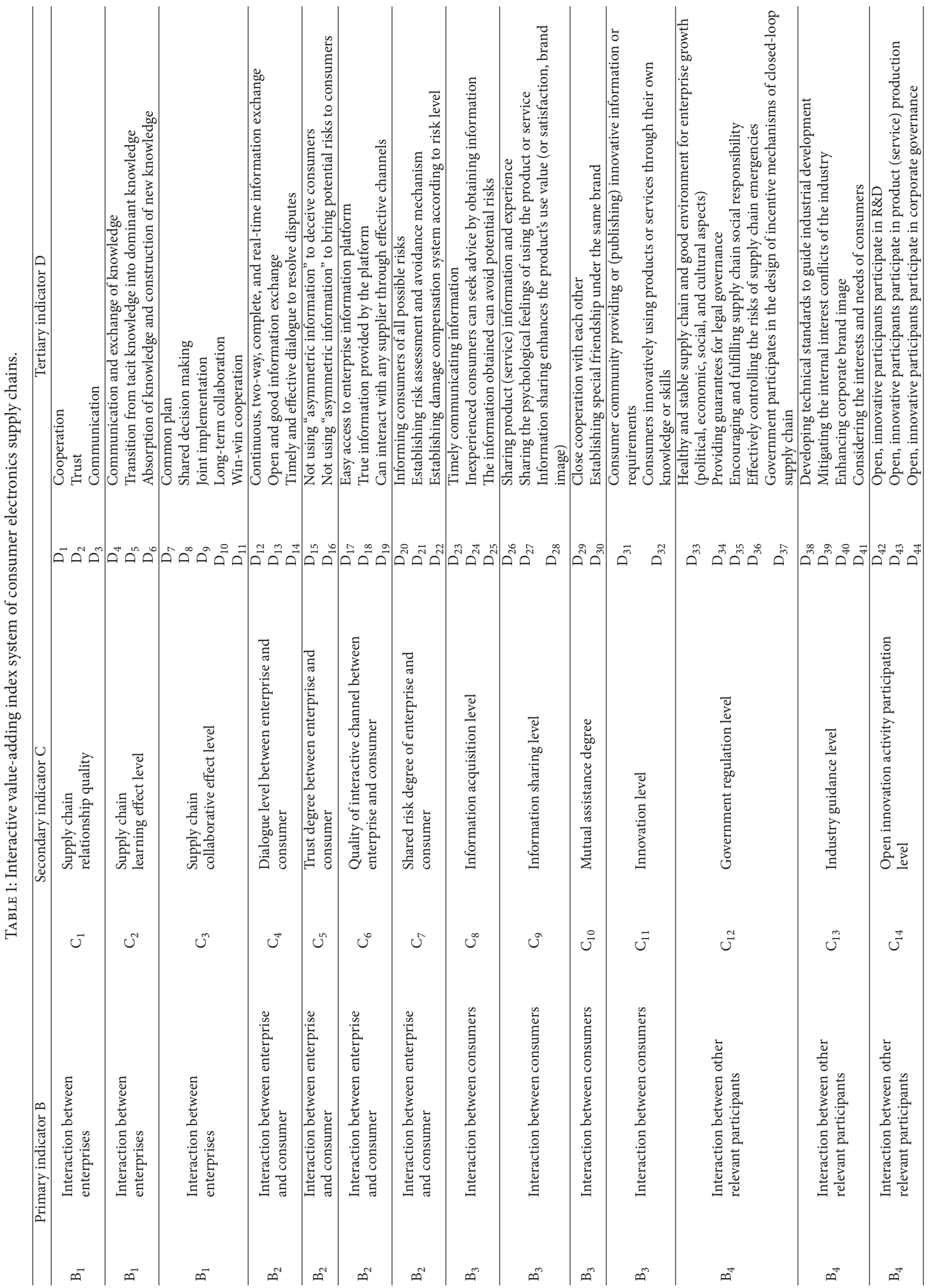


In the forecasting model, the commonly used kernel functions include the polynomial kernel function (POLY; $\left.K\left(x_{i}, x_{j}\right)=\left(x_{i}, x_{j}+b\right)^{d}\right)$, linear kernel function (LINEAR; $\left.K\left(x_{i}, x_{j}\right)=\left(x_{i}, x_{j}\right)^{d}\right)$, and sigmoid kernel function $\left(K\left(x_{i}, x_{j}\right)=\tanh \left[c_{1}\left(x_{i}, x_{i}\right)+c_{2}\right]\right)$. In these kernel functions, the form of the radial basis kernel function (RBF kernel) is as follows:

$$
K\left(x_{i}^{v}, x_{j}^{v}\right)=\exp \left(\frac{\left\|x_{i}^{v}-x_{j}^{v}\right\|}{2\left(\delta^{v}\right)^{2}}\right) .
$$

$b$ and $d$ in POLY must be adjusted and optimized. Thus, $c_{1}$ and $c_{2}$ in the sigmoid kernel function are uncertain, and LINEAR is a special case of the RBF kernel. The RBF kernel only comprises one nuclear parameter $\delta$, and such simple structure makes it widely used for research. This study establishes LS-SVM models on the basis of different kernel functions to compare the performance of the RBF kernel and that of the other kernel functions. Moreover, this study performs a comparative analysis of the effect of kernel functions on model accuracy.

\subsection{Model Solution}

3.3.1. Model Parameter Optimization. The analysis in Section 3.1 indicates that the learning and generalization capabilities of the data-driven model greatly depend on the penalty coefficient $\gamma$ and kernel function parameter $\delta$. The grid search algorithm (GSA) is a popular method used to obtain the optimal solution of $(\gamma, \delta)$ [42]. Therefore, this study adopts the GSA to determine the two parameters for conducting the $k$-fold cross-validation of each set of parameters. However, errors are caused by different initial search areas when using the GSA embedded in the MATLAB LS-SVM toolbox (version 1.8). Therefore, this study tests the combinations of primary indicators for $m$ times to ensure that the selected parameter achieves good adaptability. The average relative error is considered as the error of the model at the indicator level. Considering that the index system is constituted by three levels, the final error of the model is defined as the average error of the indicator model at different levels to ensure the consistency of the model.

If $h$ test samples are under the $v$ th level indicator, then the previous section assumes that $n$ samples exist in the training set; thus, $C_{h+n}^{n}$ combinations exist. In the sth combination, the average relative error of the corresponding training set is

$$
\begin{aligned}
& e_{s}^{\text {train }} \\
& =\frac{(1 / m) \sum_{j=1}^{m} \sum_{v=1}^{3} \sum_{i=1}^{n}\left|y_{i}-\left(\sum_{k=1}^{n} a_{k}^{v} K\left(x_{i}^{v}, x_{k}^{v}\right)+b^{v}\right)\right|}{y_{i}} .
\end{aligned}
$$

The total error evaluation function is

$$
e_{s}=\frac{e_{s}^{\text {train }}}{3(h+n)}
$$

3.3.2. Comparison and Optimization of Training Set and Test Set. The robustness and generalization ability of the LS-SVM model are affected by the number of training sets. This study produces an optimized design for each ratio of the test set over the training set to determine the optimal number of training sets. First, the ratio-related average relative error is defined as $E^{h}=\left(1 / C_{h+n}^{h}\right) \sum_{s=1}^{C_{h+n}^{h}} e_{s}$. Then, the average relative error-standard deviation relationship between the number of test sets $h$ and $E^{h}$ is observed. The test set sample $h^{*}$ that produces a small $E^{h}$ and small standard deviation is selected. Finally, according to Formula (9), all the combinations with the smallest "training set-test set" combinations are chosen. The penalty coefficient of the sample $\gamma^{v}$ and the width of the kernel function $\delta^{v}$ are calculated according to corresponding indicators.

3.3.3. LS-SVM Algorithm for Limited Samples. The LS-SVM algorithm of consumer electronics supply chains that is suitable for limited samples is obtained through the preceding analysis.

If the number of test set samples is $h$, then the number of training set samples is $n$, and the total number of samples is $N=h+n$. For each $h$, the total number of training set combinations is $p_{h}=C_{N}^{h}$. $m$ is the number of repeated tests. $v(v=1,2,3)$ is the level of indicator.

Step 1. All the $v$ th indicators of $N$ are quantified and scored to derive $\left\{x_{l}^{v}, y_{l}\right\}_{l=1}^{N}$, which is the original data set of the datadriven model of consumer electronics supply chains.

Step 2. As for all $h=1, \ldots, N-1$, the grid fivefold cross-validation method is adopted to calculate all the corresponding parameter combinations $\left(\gamma_{1}, \delta_{1}\right), \ldots,\left(\gamma_{p_{h}}, \delta_{p_{h}}\right)$ of combinations $S_{1}, \ldots, S_{p_{h}}$. The calculation is repeated for $m$ times. According to Formulas (8)-(9), the total average error of tertiary indicator $e_{1}, \ldots, e_{s_{p_{h}}}$ is calculated. Then, $E^{h}=e_{1}+$ $\cdots+e_{s_{p_{h}}}$, and the total average relative error is obtained.

Step 3. According to the relationship $h-E^{h}$, the low value of $E^{h}$ and a number of selected test sets are considered, and the optimal $h^{*}$ is selected.

Step 4. As for the optimal $h^{*}$, all the corresponding parameter combinations $\left(\gamma_{1}, \delta_{1}\right), \ldots,\left(\gamma_{p_{h}}, \delta_{p_{h}}\right)$ of combinations $S_{1}, \ldots, S_{p_{h}}$ are calculated. The calculation is repeated for $m$ times. According to Formulas (8)-(9), the total average error of tertiary indicator $e_{1}, \ldots, e_{s_{p_{h}}}$ is calculated, and the smallest error is selected and recorded as $e_{s}^{*}$. The corresponding optimal combination is $S_{s}^{*}$.

Step 5. The grid fivefold cross-test method is adopted to analyze $S_{s}^{*}$. The indicator of each level $\left(\gamma^{*}, \delta^{*}\right)$ is calculated.

Step 6. Parameter combination $\left(\gamma^{*}, \delta^{*}\right)$ is substituted into Formula (5). Then, solution $\left(a^{v}, b^{v}\right)$ is obtained. According to Formula (6), the LS-SVM-based data-driven model of each level indicator can be calculated. 
TABLE 2: Smartphone market in China (quarter 3, 2015).

\begin{tabular}{lcc}
\hline Brand number & Brand name & Market share (\%) \\
\hline A & Xiaomi & 16.4 \\
B & Huawei & 16.2 \\
C & Apple & 12.1 \\
D & OPPO & 10.2 \\
E & Vivo & 10.0 \\
F & Samsung & 8.8 \\
G & Meizu & 6.7 \\
H & Coolpad & 4.8 \\
I & Lenovo & 4.4 \\
J & ZTE & 2.7 \\
& Others & 7.6 \\
\hline
\end{tabular}

Source: HIS Technology, 2015 [43].

\section{Empirical Analysis of Smartphone Supply Chain}

4.1. Data Sources and Preprocessing. This study selects the data on the market share of the top 10 consumer electronic product brands in the Chinese market in the third quarter of 2015; the data are retrieved from the report released by HIS Technology [43] (Table 2).

This study starts from a practical point of view. The market share represents the value creation level of the supply chain. Therefore, the real value of the value creation system of the consumer electronics supply chain may be assumed to be approximately equal to its market share and is represented by $\vec{Y}$. Then, $\vec{Y}=\left(y_{1}, y_{2}, \ldots, y_{10}\right)^{\tau}=(0.164$, $0.162,0.121,0.102,0.1,0.088,0.067,0.048,0.044,0.027,0.076)$. The senior management representatives of the aforementioned top 10 brands were invited to rate the interactive value-adding index system of the supply chain using a five-point Likert scale. The scores constitute the system's input vector $x_{k}^{v}, v=1,2,3$.

This study implements the $z$-score standardization of all the independent variables and dependent variables of the samples to achieve a good model fit (the data on each dimension are changed into the data with a mean value of 0 and a variance of 1 ).

4.2. Optimal Ratio of Training Set over Test Set. The mean value of all the possible combinations $e_{i}(\gamma, \delta)$ of each $n$ is calculated according to Formulas (8)-(9) to determine the optimal number of training sets $n(n=2,3, \ldots, 9)$. The $h-E^{h}$ relationship diagram of the indicator at each level is obtained.

As shown in Figures 2-4, the abscissa represents the number of test sets, whereas the ordinate represents the mean relative error. With the increase in the number of test sets, the number of training sets gradually decreases, and the mean relative error and variance increase. Therefore, the margin of error variation caused by the increase in the total number of samples and test sets is considered when the ratio of the training set over the test set is $7: 3$. The mean relative error and the variance of the model reach the acceptable range, and the validity of model can be tested well when three test

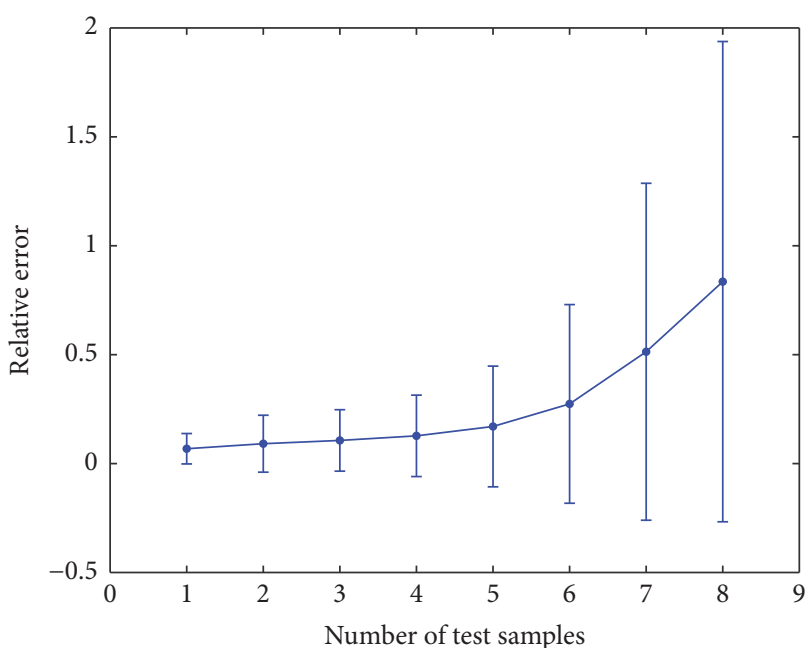

FIGURE 2: $h-E^{h}$ diagram of primary indicator.

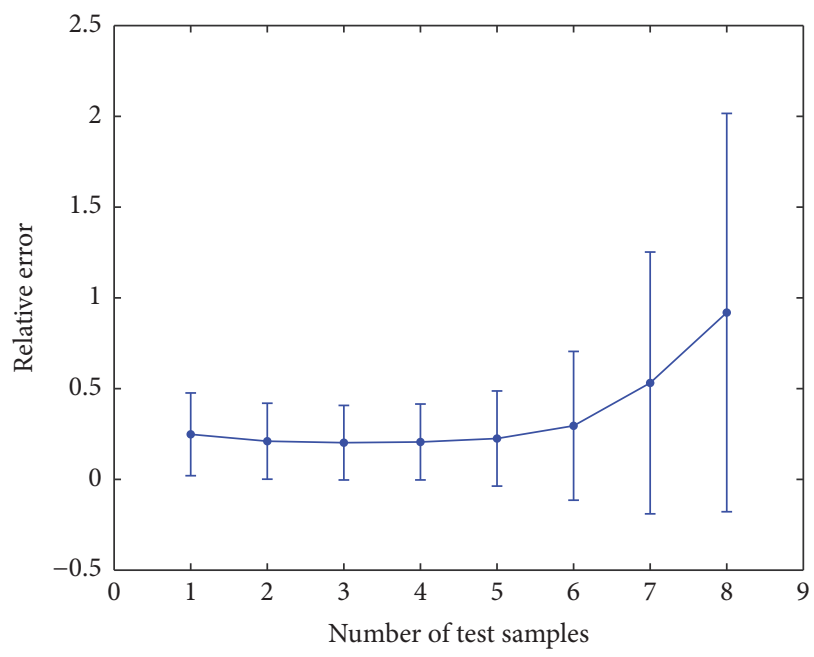

FIGURE 3: $h-E^{h}$ diagram of secondary indicator.

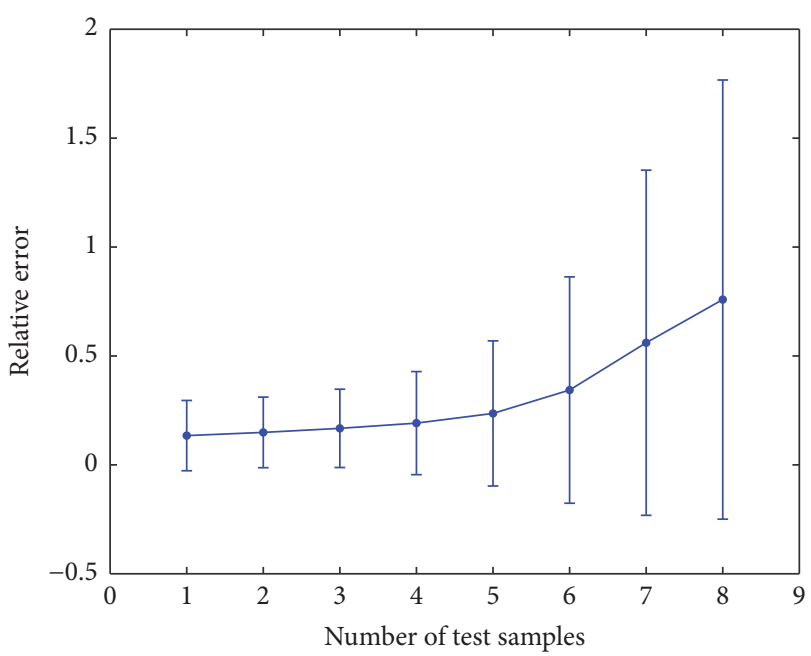

FIGURE $4: h-E^{h}$ diagram of tertiary indicator. 
sets are kept. In addition, the selected optimal proportion $h^{*}$ can prove that the literature [30] sets the proportion of the training set over the test set as $3: 1$; evidence and practical experimental methods are provided.

4.3. Determination of Modeling Parameters. According to the proportion of "training set-test set" determined in Section 4.2, 7 out of the 10 samples are randomly selected as training sets. The remaining three samples are set as test sets, thereby forming $C_{10}^{3}$ "training set-test set" combinations. This study determines the optimal penalty coefficient $\gamma$ and the width value $\gamma$ using the MATLAB LS-SVM toolbox (version 1.8) program and fivefold cross-validation. However, allocating the LS-SVM toolbox (version 1.8) causes uncertain $\gamma$ and $\delta$ interval. Therefore, this study runs the $C_{10}^{3}$ "training set-test set" combinations for 50 times $(m=50)$ to ensure the generality of the selected training set. A set of training sets that achieves the minimum relative error between the predictive value of the test set $y_{\text {smartphone }}^{v}$ and the actual value $y_{i}$ is selected from the operating results and is set as the training set of the model. The $\gamma, \delta, \vec{a}$, and $b$ of the training set are calculated.

4.4. Model Construction. This study tests the primary indicators according to the aforementioned algorithm and calculates the model parameters; namely, $\gamma^{1}=6688.5436$, $\delta^{1}=9.3824, a^{1}=(-1.410,3.713,-0.1716,0.7713,-3.6011$, $1.1173,-0.4185)^{\tau}$, and $b^{1}=0.0904$, when they are substituted into Formula (6). Model (10) can be obtained as follows:

$$
y_{\text {smartphone }}^{1}\left(x^{1}\right)=\sum_{k=1}^{n} a_{k}^{1} K\left(x^{1}, x_{k}^{1}\right)+b^{1} .
$$

Similarly, secondary indicators are tested, and model parameter values, namely, $\gamma^{2}=42.2070, \delta^{2}=94.4815, a^{2}=$ $(3.1259,9.3600,-3.4464,-6.3903,-4.0192,4.8775,-3.5075)^{\tau}$, and $b^{2}=0.3462$, are obtained when they are substituted into Formula (6). Model (11) can be obtained as follows:

$$
y_{\text {smartphone }}^{2}\left(x^{2}\right)=\sum_{k=1}^{n} a_{k}^{2} K\left(x^{2}, x_{k}^{2}\right)+b^{2} .
$$

Similarly, tertiary indicators are tested, and the model parameter values, namely, $\gamma^{3}=395.1913, \delta^{3}=315.5547$, $a^{3}=(-2.3749,21.1087,-11.0490,-3.6557,-7.9159,7.2021$, $-3.3873)^{\tau}$, and $b^{3}=0.2903$, are obtained when they are substituted into Formula (6). Model (12) can be obtained as follows:

$$
y_{\text {smartphone }}^{3}\left(x^{3}\right)=\sum_{k=1}^{n} a_{k}^{3} K\left(x^{3}, x_{k}^{3}\right)+b^{3} .
$$

4.5. Result Analysis. According to Models (10)-(12), the comparison between the output values (predictive value) and the actual values of the indicators at different levels is shown in Figures 5-7.

In Figures 5-7, the ordinate represents the market share, whereas the abscissa represents the sample. In the test set

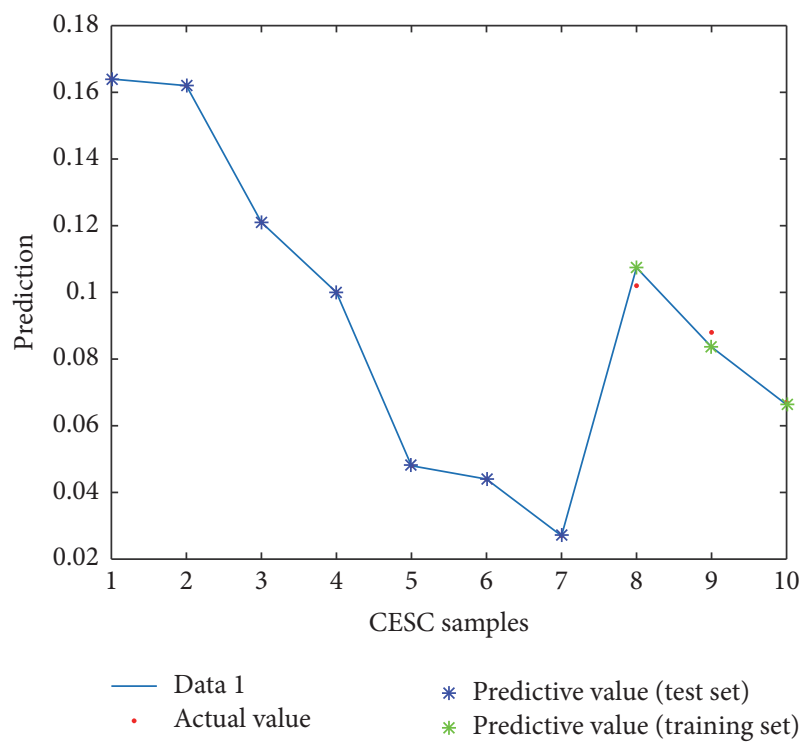

Figure 5: Output of data-driven model and actual value based on primary indicators.

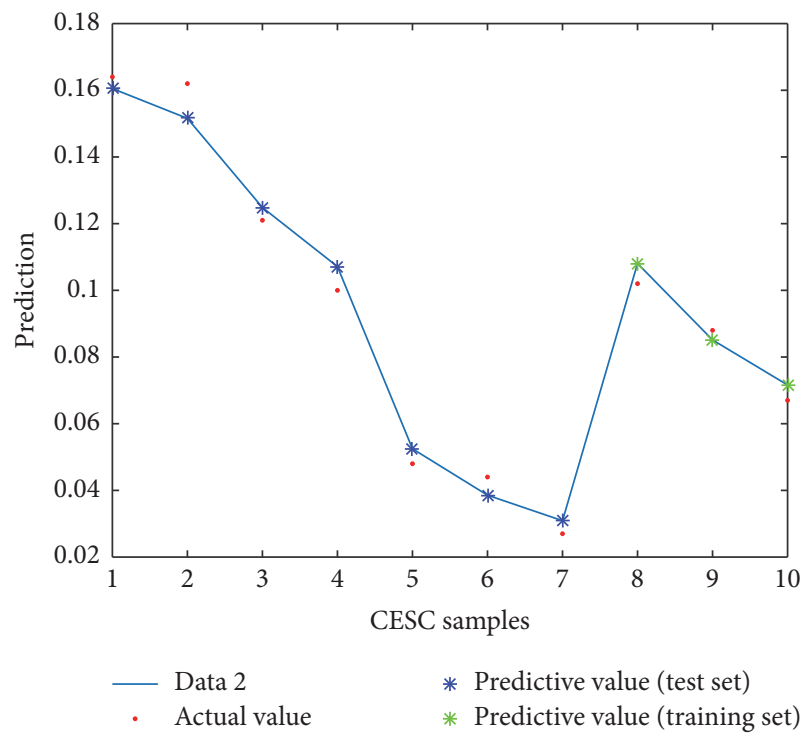

FIgURE 6: Output of data-driven model and actual value based on secondary indicators.

of the smartphone data-driven model based on primary, secondary, and tertiary indicators, the mean relative errors between the predictive values and the actual values are $3.76 \%$, $5.36 \%$, and $2.42 \%$, respectively. From this perspective, the data-driven models (10)-(12) of the smartphone interactive value-adding system show a high prediction accuracy. With regard to the optimal combination determined in Section 4.3, the test set consists of OPPO, Samsung, and Meizu, whereas the remaining seven brands constitute the training set.

Given that the model is effective, the value-adding influence factor of the consumer electronics supply chain and the index system extracted and constructed by this study, respectively, are scientific and effective. They also 


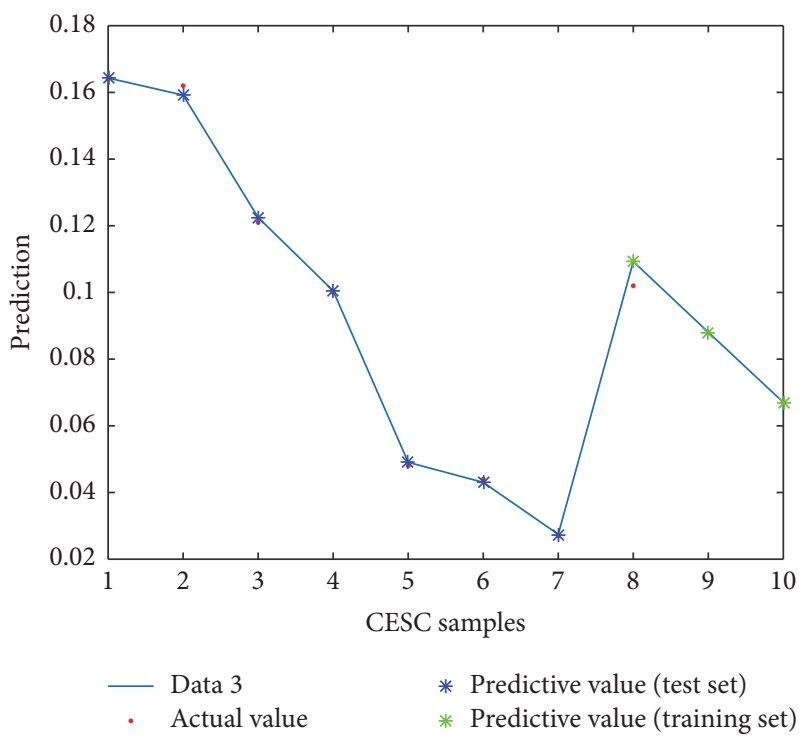

FIGURE 7: Output of data-driven model and actual value based on tertiary indicators.

appropriately reflect the value creation system of a specific industrial supply chain. In terms of prediction accuracy, the model based on tertiary indicators should be adopted when analyzing the market share of consumer electronics enterprises because this model achieves the highest precision. In terms of convenience, the model based on primary indicators is the best because this model contains few indicators and it can obtain data easily.

The scientific index system segments the value creation system of consumer electronics enterprises and demonstrates the value-adding mechanism. This system can help consumer electronics companies to determine the value-adding points accurately. Consumer electronics companies can also learn from model enterprises, compare the inputs of their interactive value-adding systems, and perform a scientific analysis on their differences to select investment strategies, improve business outputs, and reduce investment.

\section{Comparative Analysis}

5.1. Comparison of the Accuracies of Different Models. This study combines the training set and test set determined in Section 4.3 to compare the advantages and disadvantages of LS-SVM and other prediction methods. The prediction models based on SVM, extreme learning machines (ELM), and back propagation (BP) are also established. The predictive values of the test set in different models and their relative errors are shown in Table 3.

Table 3 shows the mean errors and standard deviations of the predictive values of the test sets of the different LSSVM models based on indicator data at different levels and different kernel functions. They are ranked in ascending order as follows: LS-SVM $<$ SVM $<\mathrm{BP}<\mathrm{ELM}$. The data-driven model based on the LS-SVM method shows the lowest mean

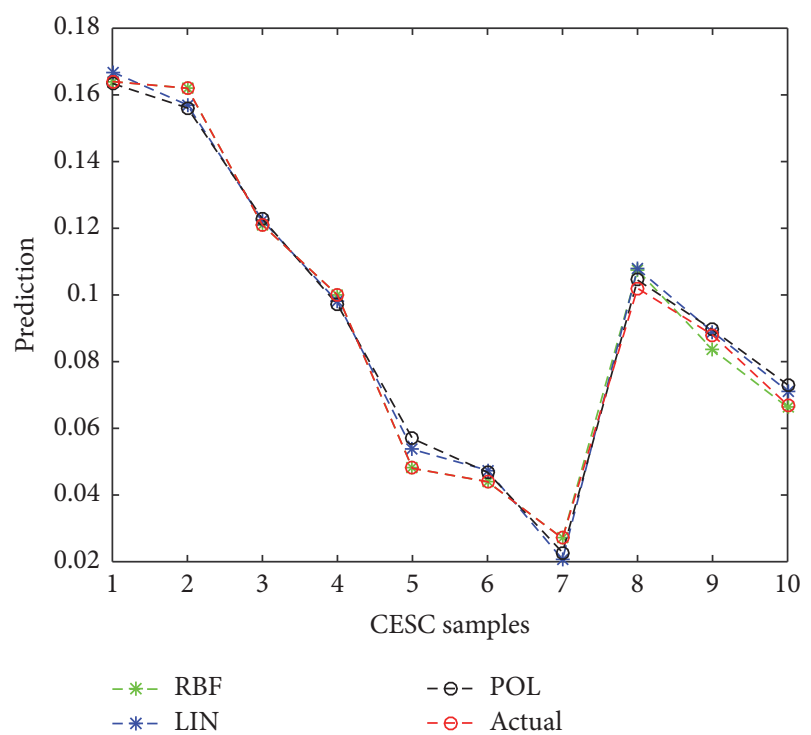

FIGURE 8: Effect of kernel function selection on the accuracy of the LS-SVM model (primary indicators).

error and standard deviation and is thus superior to the other models.

5.2. Effect of Kernel Function Selection on LS-SVM Model Accuracy. This section debugs the common RBF kernel, LINEAR, and POLY, which are all constructs of the LS-SVM model, to investigate the effect of kernel function selection on the data-driven model (Figures 8-10 and Table 4). Figures 8-10 show that the predictive values of the LS-SVM model based on the RBF kernel show the best fitting effect with the actual value, the minimum mean error, and the highest performance.

As shown in Table 4, when the models are based on primary indicator data, the average relative errors of the predictive values of the LS-SVM models based on the three kernel functions are ranked in ascending order as follows: RBF $<$ POLY < LINEAR (all sets); RBF $<$ POLY = LINEAR (test set). When the models are based on secondary indicator data, the average relative errors of the predictive values are ranked in ascending order as RBF < LINEAR $<$ POLY (all sets) and RBF $<$ POLY $<$ LINEAR (test set). When the models are based on secondary tertiary indicator data, the average relative errors of the predictive values in all sets and in the test set are ranked in ascending order as follows: RBF < LINEAR < POLY. Therefore, the training set of the LS-SVM model based on the RBF kernel shows a better fitting degree than the other kernel functions. The RBF kernel performs better than the other kernel functions regardless of the prediction accuracy of all the sets or test sets.

\section{Conclusions}

This study establishes a value creation system of consumer electronics supply chains on the basis of the theory of value cocreation and the interactive value-adding mechanism 


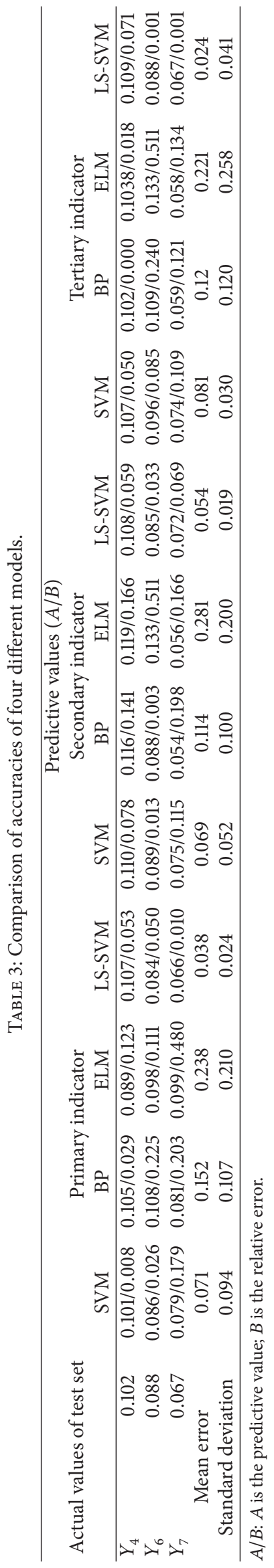


TABLE 4: Comparison of the accuracies of the LS-SVM models based on different kernel functions.

\begin{tabular}{|c|c|c|c|c|c|c|c|c|c|}
\hline \multirow{2}{*}{ Samples } & \multicolumn{3}{|c|}{ Primary indicator } & \multicolumn{3}{|c|}{ Secondary indicator } & \multicolumn{3}{|c|}{ Tertiary indicator } \\
\hline & RBF & LINEAR & POLY & RBF & LINEAR & POLY & $\mathrm{RBF}$ & LINEAR & POLY \\
\hline \multirow{7}{*}{ Training set } & 0.000 & 0.018 & 0.003 & 0.021 & 0.021 & 0.040 & 0.002 & 0.003 & 0.003 \\
\hline & 0.000 & 0.031 & 0.036 & 0.044 & 0.054 & 0.100 & 0.017 & 0.014 & 0.024 \\
\hline & 0.000 & 0.012 & 0.015 & 0.032 & 0.022 & 0.045 & 0.012 & 0.008 & 0.015 \\
\hline & 0.000 & 0.020 & 0.029 & 0.071 & 0.096 & 0.093 & 0.005 & 0.005 & 0.009 \\
\hline & 0.000 & 0.118 & 0.186 & 0.093 & 0.094 & 0.188 & 0.022 & 0.022 & 0.041 \\
\hline & 0.000 & 0.078 & 0.064 & 0.124 & 0.135 & 0.102 & 0.022 & 0.012 & 0.022 \\
\hline & 0.000 & 0.234 & 0.157 & 0.145 & 0.050 & 0.127 & 0.017 & 0.006 & 0.010 \\
\hline \multirow{3}{*}{ Test set } & 0.053 & 0.057 & 0.024 & 0.059 & 0.085 & 0.082 & 0.071 & 0.072 & 0.076 \\
\hline & 0.050 & 0.011 & 0.018 & 0.033 & 0.022 & 0.016 & 0.001 & 0.044 & 0.044 \\
\hline & 0.010 & 0.063 & 0.091 & 0.069 & 0.190 & 0.134 & 0.001 & 0.062 & 0.075 \\
\hline Mean error (test set) & 0.038 & 0.044 & 0.044 & 0.054 & 0.099 & 0.077 & 0.024 & 0.059 & 0.065 \\
\hline Mean error (all sets) & 0.011 & 0.064 & 0.062 & 0.071 & 0.077 & 0.093 & 0.017 & 0.025 & 0.032 \\
\hline
\end{tabular}

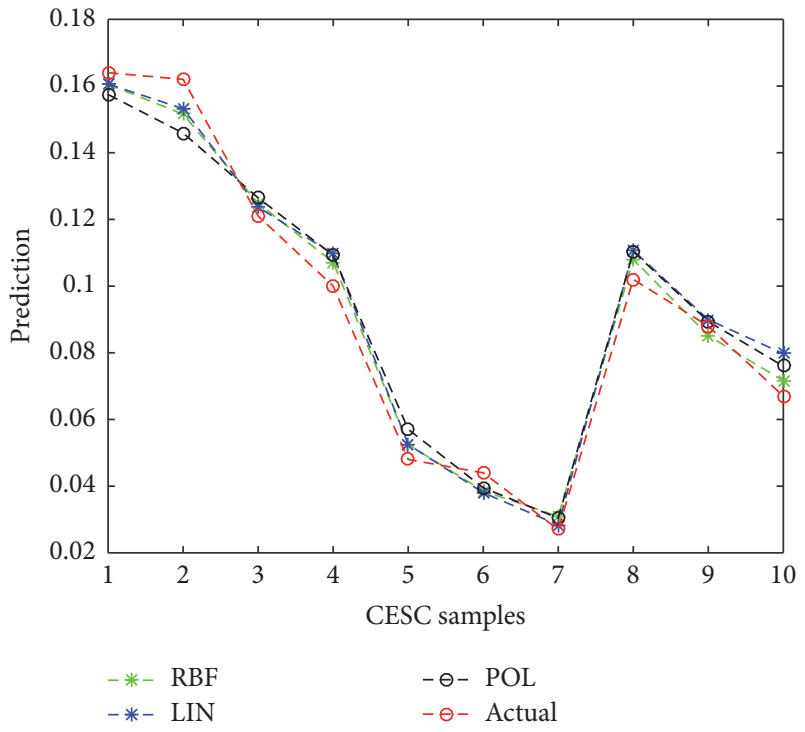

FIGURE 9: Effect of kernel function selection on the accuracy of the LS-SVM model (secondary indicators).

between value creators in supply chains. Therefore, this study adopts the LS-SVM method to construct a data-driven model of consumer electronics supply chains and proposes the LSSVM algorithm, which is suitable for limited samples for consumer electronics supply chains. On the basis of this algorithm and the marginal effect, this study presents a good proportion of the training set over the test set under the condition involving a small number of data samples. Finally, this study performs an empirical analysis of the top 10 smartphone supply chains in the Chinese market. The results indicate that the model achieves a good prediction accuracy. This research can help consumer electronics enterprises to accurately determine value-adding points and conduct market analyses. This study also provides a great practical value to improve the competitiveness of the consumer electronics supply chains of these enterprises.

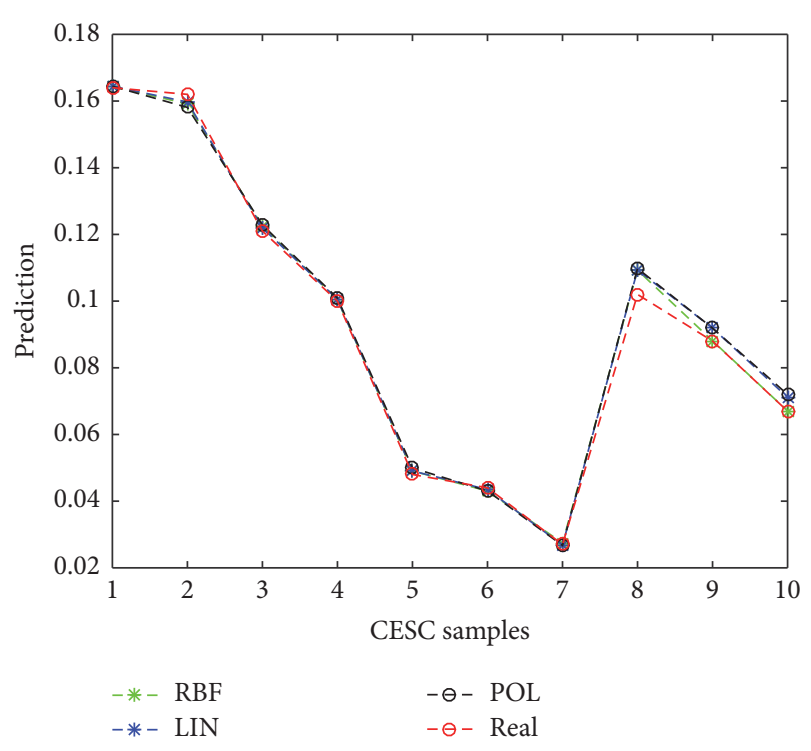

FIGURE 10: Effect of kernel function selection on the accuracy of the LS-SVM model (tertiary indicators).

The subsequent research will perform an in-depth analysis of the value creation mechanism of consumer electronics supply chains. The features will be selected according to the established index system and data-driven model, and the optimal investment strategy for consumer electronics supply chain investment will be determined.

\section{Competing Interests}

The authors declare that there are no competing interests regarding the publication of this paper.

\section{Acknowledgments}

This study is supported by the National Nature Science Foundation of China (NSFC) (Grant no. 71572096). 


\section{References}

[1] S. B. Wath, A. N. Vaidya, P. S. Dutt, and T. Chakrabarti, "A roadmap for development of sustainable E-waste management system in India," Science of the Total Environment, vol. 409, no. 1, pp. 19-32, 2010.

[2] China Consumer Electronics Report 2015, China Consumer Electronics Report, Business Source Complete, EBSCO Information Services, Ipswich, Mass, USA, 2016.

[3] X. P. Shen, "Value system and competitive advantage of supply chain," Logistics Engineering and Management, no. 8, pp. 137139, 2010.

[4] J. C. Anderson and J. A. Narus, Business Market Management: Understanding, Creating, and Delivering Value, Pearson Prentice Hall, Upper Saddle River, NJ, USA, 2nd edition, 2004.

[5] N. Mizik and R. Jacobson, "Trading off between value creation and value appropriation: the financial implications of shifts in strategic emphasis," Journal of Marketing, vol. 67, no. 1, pp. 6376, 2003.

[6] S. L. Vargo and R. F. Lusch, "Evolving to a new dominant logic for marketing," Journal of Marketing, vol. 68, no. 1, pp. 1-17, 2004.

[7] C. K. Prahalad and V. Ramaswamy, The Future of Competition: Co-Creating Unique Value with Customers, Harvard Business School Press, Boston, Mass, USA, 2004.

[8] A. R. Sakamoto, C. B. Villar, and M. E. Martins, Open Innovation and Collaborative Network in Supply Chain: The Case of Open IPTV Forum, IGI Global, Hershey, Pa, USA, 2012.

[9] D. Aksen, N. Aras, and A. G. Karaarslan, "Design and analysis of government subsidized collection systems for incentivedependent returns," International Journal of Production Economics, vol. 119, no. 2, pp. 308-327, 2009.

[10] H. H. Liu, M. Lei, H. H. Deng, G. K. Keong Leong, and T. Huang, "A dual channel, quality-based price competition model for the WEEE recycling market with government subsidy," Omega, vol. 59, pp. 290-302, 2016.

[11] P.-H. Qiao, X.-F. Ju, and H.-G. Fung, "Industry association networks, innovations, and firm performance in Chinese small and medium-sized enterprises," China Economic Review, vol. 29, no. 6, pp. 213-228, 2014.

[12] J. H. Xiao, K. Xie, Y. Wu, and X. H. Liao, "The supply chain transformation from being partner from being partneroriented to being customer oriented: a double-case study on the supply chains in ecommerce enterprises," Management World, no. 4, pp. 137-154, 2015.

[13] Q. C. Meng, J. H. Dong, and C. C. Li, "Study on supply chain value maximization based on new prosumer," Chinese Journal of Management Science, vol. 20, no. 6, pp. 102-109, 2012.

[14] Q. C. Meng and H. H. Li, "A study on supply chain value maximization considering the competition between supply chains based on new prosumer," Chinese Journal of Management Science, vol. 23, no. 3, pp. 168-176, 2015.

[15] S. Huang, S. Zeng, Y. Fan, and G. Q. Huang, "Optimal service selection and composition for service-oriented manufacturing network," International Journal of Computer Integrated Manufacturing, vol. 24, no. 5, pp. 416-430, 2011.

[16] S. Cavalieri and G. Pezzotta, "Product-service systems engineering: state of the art and research challenges," Computers in Industry, vol. 63, no. 4, pp. 278-288, 2012.

[17] L. Zhen, "An analytical study on service-oriented manufacturing strategies," International Journal of Production Economics, vol. 139, no. 1, pp. 220-228, 2012.
[18] Y. Y. Niu, "Research on the influence of cluster supply chain network under the paradigm of open innovation," Value Engineering, no. 15, pp. 64-67, 2015.

[19] HignBeam Business, IBM Opens Supply Chain Innovation Center in China, HignBeam Business, Industry Week/IW, Chicago, Ill, USA, 2008.

[20] R. F. Lusch, S. L. Vargo, and M. O’Brien, "Competing through service: insights from service-dominant logic," Journal of Retailing, vol. 83, no. 1, pp. 5-18, 2007.

[21] M. S. Yadav and P. R. Varadarajan, "Understanding product migration to the electronic marketplace: a conceptual framework," Journal of Retailing, vol. 81, no. 2, pp. 125-140, 2005.

[22] C. Grönroos, "Service logic revisited: who creates value? And who co-creates?" European Business Review, vol. 20, no. 4, pp. 298-314, 2008.

[23] D. Ballantyne and R. J. Varey, "Creating value-in-use through marketing interaction: the exchange logic of relating, communicating and knowing," Marketing Theory, vol. 6, no. 3, pp. 335348, 2006.

[24] G. Ramani and V. Kumar, "Interaction orientation and firm performance," Journal of Marketing, vol. 72, no. 1, pp. 27-45, 2008.

[25] R. T. Rust, C. Moorman, and G. Bhalla, "Rethinking marketing," Harvard Business Review, vol. 88, no. 4, pp. 94-101, 2010.

[26] J. C. Xu, Q. W. Ren, and Z. Z. Shen, "Prediction of the strength of concrete radiation shielding based on LS-SVM," Annals of Nuclear Energy, vol. 85, pp. 296-300, 2015.

[27] H. M. Khalil and M. El-Bardini, "Implementation of speed controller for rotary hydraulic motor based on LS-SVM," Expert Systems with Applications, vol. 38, no. 11, pp. 14249-14256, 2011.

[28] T.-C. Lin, "A multi-class dempster classifier with support vector machine for image enhancement," International Journal of Innovative Computing, Information and Control, vol. 11, no. 5, pp. 1639-1654, 2015.

[29] R. Langone, C. Alzate, B. D. Ketelaere, J. Vlasselaer, W. Meert, and J. A. K. Suykens, "LS-SVM based spectral clustering and regression for predicting maintenance of industrial machines," Engineering Applications of Artificial Intelligence, vol. 37, pp. 268-278, 2015.

[30] N. Zhang and D. Shetty, "An effective LS-SVM-based approach for surface roughness prediction in machined surfaces," Neurocomputing, vol. 198, pp. 35-39, 2016.

[31] X. H. Yuan, C. Chen, Y. B. Yuan, Y. H. Huang, and Q. X. Tan, "Short-term wind power prediction based on LSSVM-GSA model," Energy Conversion and Management, vol. 101, pp. 393401, 2015.

[32] H. H. Yu, Y. Y. Chen, S. G. Hassan, and D. L. Li, "Prediction of the temperature in a Chinese solar greenhouse based on LSSVM optimized by improved PSO," Computers and Electronics in Agriculture, vol. 122, pp. 94-102, 2016.

[33] J. Wu, X. Cui, T. Nishi, and J. Li, "Game theoretic approach for coordination of telecommunication supply chain under network externality," International Journal of Innovative Computing, vol. 12, no. 3, pp. 915-928, 2016.

[34] H. C. Jung, J. S. Kim, and H. Heo, "Prediction of building energy consumption using an improved real coded genetic algorithm based least squares support vector machine approach," Energy and Buildings, vol. 90, pp. 76-84, 2015.

[35] D. A. Silva, J. P. Silva, and A. R. Rocha Neto, "Novel approaches using evolutionary computation for sparse least square support vector machines," Neurocomputing, vol. 168, pp. 908-916, 2015. 
[36] C. Durugbo and K. Pawar, "A unified model of the co-creation process," Expert Systems with Applications, vol. 41, no. 9, pp. 4373-4387, 2014.

[37] A. F. Payne, K. Storbacka, and P. Frow, "Managing the cocreation of value," Journal of the Academy of Marketing Science, vol. 36, no. 1, pp. 83-96, 2008.

[38] H. Saarijärvi, P. K. Kannan, and H. Kuusela, "Value co-creation: theoretical approaches and practical implications," European Business Review, vol. 25, no. 1, pp. 6-19, 2013.

[39] N. Pinho, G. Beirão, L. Patrício, and R. P. Fisk, "Understanding value co-creation in complex services with many actors," Journal of Service Management, vol. 25, no. 4, pp. 470-493, 2014.

[40] X. L. Wan and Q. C. Meng, "Construction and capacity determination of supply chain interaction value-added index system from the perspective of co-creation," Working Paper, 2016.

[41] C. Cortes and V. Vapnik, "Support-vector networks," Machine Learning, vol. 20, no. 3, pp. 273-297, 1995.

[42] X. Juncai, R. Qingwen, and S. Zhenzhong, "Prediction of the strength of concrete radiation shielding based on LS-SVM," Annals of Nuclear Energy, vol. 85, pp. 296-300, 2015.

[43] HIS Technology, China's Smartphone Market Share Report (2015Q3), HIS Technology, 2015. 

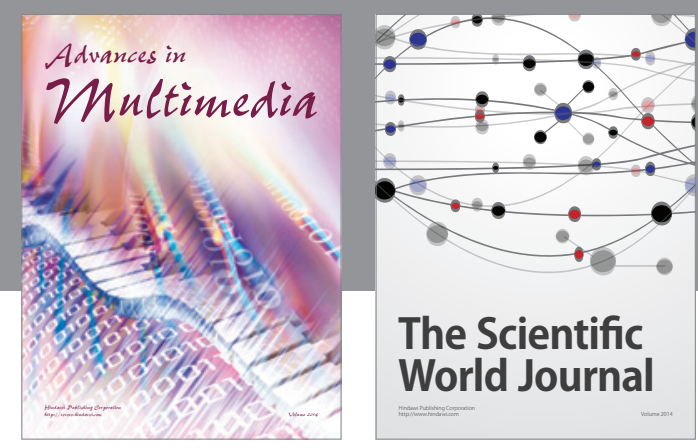

The Scientific World Journal
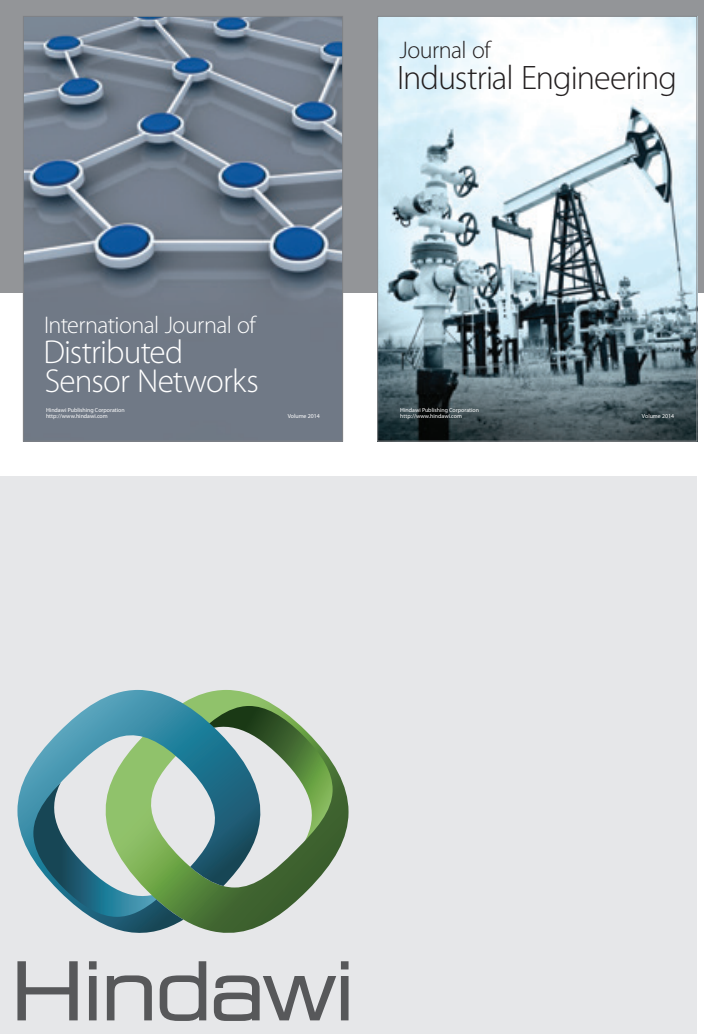

Submit your manuscripts at

http://www.hindawi.com

\section{Computer Networks} and Communications
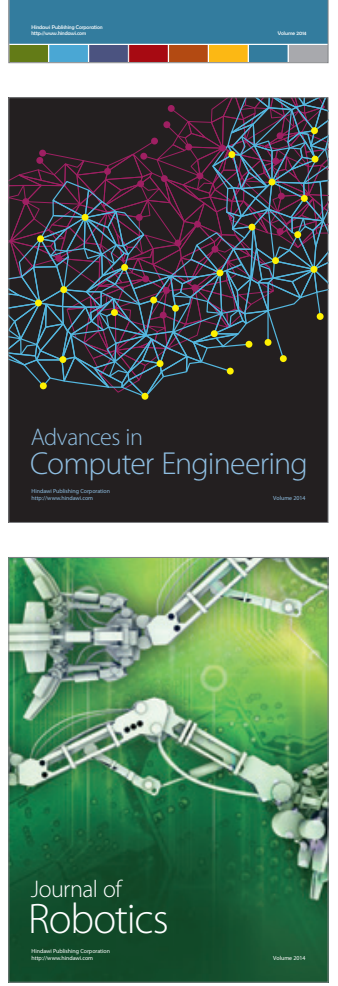
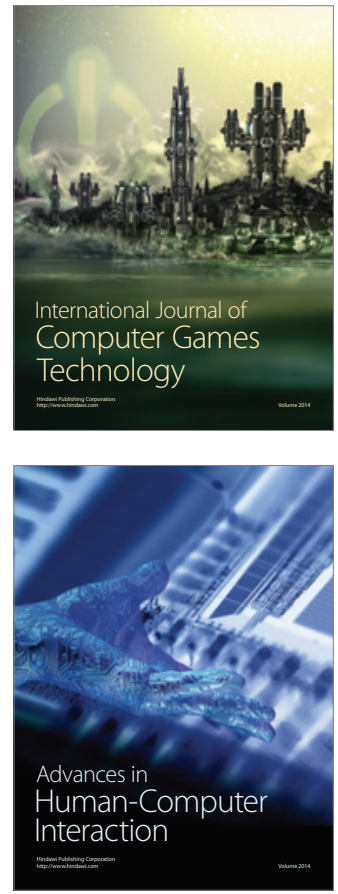
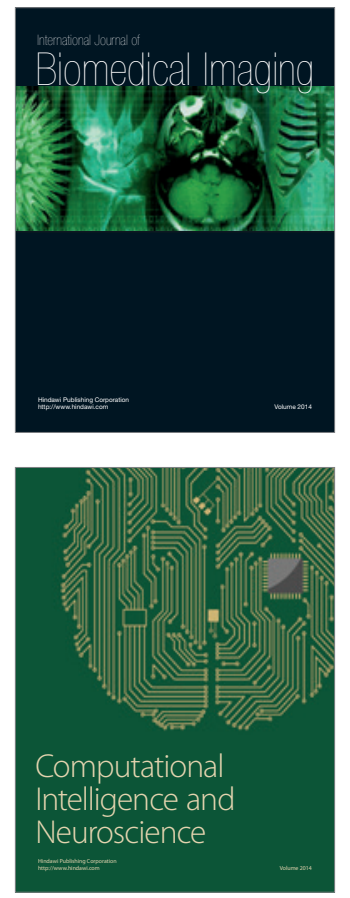
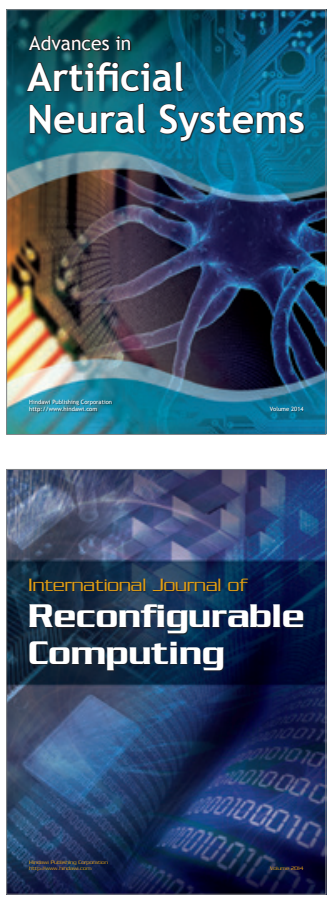
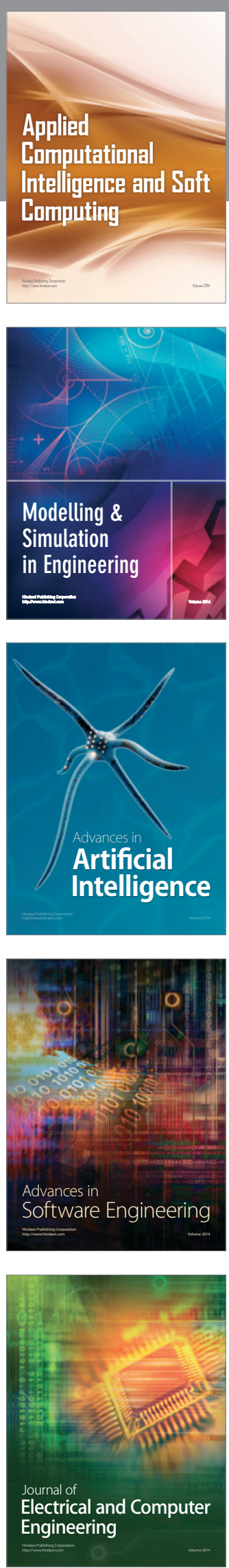